\title{
Espaços Formativos com Professores e Estudantes de Licenciaturas: Possibilidades de Escutas e Reflexões
}

\author{
Espacios Formativos con Profesores y Estudiantes de Licenciaturas: \\ Posibilidades de Escuchas y Reflexiones
}

\section{Educational Spaces with Teachers and Undergraduate Students: Possibilities of Listening and Reflections}

\author{
Lisiane de Pinho Coutinho da Costa $^{1}$ \\ Elaine Corrêa Pereira ${ }^{2}$ \\ Celiane Costa Machado ${ }^{3}$
}

\begin{abstract}
Resumo
O presente artigo tem como objetivo discutir e aprofundar o estudo relacionado a temática da formação de professores no âmbito da Educação Básica e Superior. Nesse sentido foram realizadas três oficinas por integrantes do Grupo de Pesquisa Formação de Professores e Práticas Educativas (FORPPE) em espaços formativos com professores e estudantes de licenciaturas. As oficinas foram: Espaços de Diálogo: O docente Protagonizando sua Prática junto a Universidade, O exercício da escrita articulado aos processos de ensinar e aprender de professores e alunos e Construção de Conceitos Matemáticos Utilizando o Software Geogebra. Estas oficinas foram ofertadas a alguns professores da rede pública de ensino e licenciandos e possibilitaram buscar e refletir acerca dos processos de ensino e a aprendizagem principalmente no que tange a realidade das escolas públicas tendo o foco de suas ações na escuta aos docentes e na formação realizada dentro do espaço escolar. As ações interdisciplinares permitiram transitar nas diferentes áreas e conhecimento de modo a investigar os problemas do ensino e aprendizagem nos diversos contextos, como escola, universidade e comunidade. De maneira geral, ocorreu um grande envolvimento de todos os participantes nas atividades realizadas.
\end{abstract}

Palavras-Chave: Aprendizagem; Educação; Formação continuada; Oficina.

\section{Resumen}

El presente artículo tiene como objetivo discutir y profundizar el estudio relacionado con la temática de la formación de profesores en el ámbito de la Educación Básica y Superior. En ese sentido se realizaron tres talleres por integrantes del Grupo de Investigación Formación de Profesores y Prácticas Educativas (FORPPE) en espacios formativos con profesores y estudiantes de licenciaturas. Los talleres fueron: Espacios de Diálogo: El docente Protagonizando su Práctica junto a la Universidad, El ejercicio de la escritura articulado a los procesos de enseñar y aprender de profesores y alumnos y Construcción de Conceptos Matemáticos Utilizando el Software Geogebra. Estos talleres fueron ofrecidos a algunos profesores de la red pública de enseñanza y licenciandos y posibilitar buscar y reflexionar acerca de los procesos de enseñanza y el aprendizaje principalmente en lo que se refiere a la realidad de las escuelas públicas teniendo el foco de sus acciones en la escucha a los docentes y en la formación realizada dentro del espacio escolar. Las acciones interdisciplinarias permitieron transitar en las diferentes áreas y

\footnotetext{
${ }^{1}$ Pós-Graduada em Educação Inclusiva; Universidade Federal do Rio do Grande - FURG; Rio Grande, Rio Grande do Sul, Brasil; lisibn@gmail.com

2 Doutora em Engenharia de Produção; Universidade Federal do Rio Grande - FURG; Rio Grande, Rio Grande do Sul, Brasil; elainepereira@prolic.furg.br

${ }^{3}$ Doutora em Matemática Aplicada; Universidade Federal do Rio Grande- FURG, Rio Grande, Rio Grande do Sul, Brasil; celianecmachado@gmail.com
} 
conocimiento para investigar los problemas de la enseñanza y el aprendizaje en los diversos contextos, como la escuela, la universidad y la comunidad. De manera general, ocurrió una gran implicación de todos los participantes en las actividades realizadas.

Palabras clave: Aprendizaje; la educación; Formación continua; Taller.

\begin{abstract}
The present article aims to discuss and deepen the study related to the theme of teacher education in the scope of Basic and Higher Education. In this sense, three workshops were held by members of the Research Group Teacher Training and Educational Practices (FORPPE) in training spaces with professors and undergraduate students. The workshops were: Spaces of Dialogue: The teacher Starring his practice with the University, The exercise of written articulation to the processes of teaching and learning of teachers and students and Construction of Mathematical Concepts Using Geogebra Software. These workshops were offered to some teachers of the public school and graduates and allowed to seek and reflect on the teaching and learning processes, mainly in relation to the reality of public schools, focusing their actions on listening to teachers and on the formation within the school space. The interdisciplinary actions allowed to transit in the different areas and knowledge in order to investigate the problems of teaching and learning in the different contexts, such as school, university and community. In general, there was a great involvement of all participants in the activities carried out.
\end{abstract}

Keywords: Learning; Education; Continuing education; Workshop.

\title{
1. Introdução
}

A educação vem sofrendo várias mudanças devido aos avanços tecnológicos, dessa forma percebe-se, por parte dos educadores, a necessidade de buscar estratégias pedagógicas com o intuito de proporcionar um aprendizado mais motivador e significativo para os educandos. Muitos professores não sabem quais caminhos usar para tentar incentivar os alunos e com isso poder proporcionar uma aprendizagem mais significativa. Sendo assim, sentem a necessidade de auxílio para enfrentar os desafios que surgem no decorrer de suas práticas docentes.

Como a Universidade Federal do Rio Grande - FURG é uma universidade pública e gratuita, e por essa razão possui o compromisso de promover a educação plena, contemplando o ensino, a pesquisa e a extensão, o Grupo de Pesquisa Formação de Professores e Prática Educativas (FORPPE) segue o mesmo contexto e ao longo dos anos vêm desenvolvendo ações que possibilitem espaços de reflexão e construção de conhecimentos e saberes que versam sobre a formação inicial e permanente de professores e de estudantes de licenciaturas. Esse grupo possui 21 integrantes, sendo esses graduandos, mestrandos, doutorandos e pesquisadores.

Dentre as atividades desenvolvidas pelo FORPPE, destaca-se o Programa e Formação Acadêmico Profissional e Práticas Educativas, o qual tem como objetivo discutir e aprofundar estudos relacionados à temática da formação de professores no âmbito da Educação Básica e Superior. O referido Programa caracteriza-se como ação de extensão abarcando também o 
ensino e a pesquisa. Neste sentido o presente artigo tem como objetivo apresentar algumas reflexões que emergem de três oficinas realizadas, no ano de 2017, por integrantes do Grupo FORPPE em espaços formativos com professores e estudantes de licenciaturas. As ações desenvolvidas foram permeadas por atividades interativas tais como: rodas de conversa, ambiente virtual de aprendizagem e escritas reflexivas sobre questões previamente elencadas. Nessa perspectiva, explorou-se permanentemente os limites e as possibilidades da interdisciplinaridade e da pesquisa em sala de aula.

Demo (2006) defende que a pesquisa é o caminho possível para uma formação mais qualificada, por proporcionar uma reflexão sobre a prática. Sendo assim, percebe-se que a formação dos professores se faz num processo de desenvolvimento continuo, contemplando as necessidades dos docentes, diante do planejamento e execução de suas práticas pedagógicas.

Entretanto, diante da realidade do sistema educacional alguns professores sentem dificuldade de investir na formação continuada, alguns por falta de oportunidade, já outros encontram dificuldades diante da intensa rotina de trabalho, o que pode tornar a participação na formação continuada um ato complexo, pois essa exige tempo e dedicação destes profissionais. Ainda, neste contexto, existem profissionais que não mostram interesse em inovar por achar que está satisfeito com a formação que possui.

Diante do exposto e movido pelas necessidades dos professores em atualizar-se o FORPPE concentra o foco de suas ações na escuta aos docentes e na formação realizada dentro do espaço escolar. Nesse sentido, desenvolve práticas pedagógicas adequadas à realidade cultural e social dos educandos, sendo assim o grupo propôs no ano de 2017 algumas oficinas, entre elas, três se destacaram: "Espaços de diálogo: o docente protagonizando sua prática junto à necessidade junto à universidade", "Construção de Conceitos Matemáticos Utilizando o Software Geogebra" e "O exercício da escrita articulando aos processos de ensinar e aprender de professores e alunos". Estas oficinas foram ofertadas a alguns professores da rede pública de ensino e licenciandos da FURG com objetivo oportunizar aos participantes um espaço de formação acadêmico profissional, propiciando reflexões frente às necessidades educacionais atuais.

\section{Formação de Professores: algumas considerações}

Freire (1996, p.43) afirma que: "É pensando criticamente a prática de hoje ou de ontem é que pode melhorar a próxima prática". Para isso é necessário o docente estar sempre em constante formação, para que se mantenha atualizado e inovando sua pratica educativa como também ampliando seu próprio conhecimento. Durante o processo de formação, o docente 
adquire experiência e conhecimento que o ajudam no seu modo de pensar e agir, como afirma Freire (1996, p. 25), “[...] quem forma se forma e reforma ao formar e quem é formado formase e forma ao ser formado". Assim, na formação, o docente estará em um movimento permanente de qualificação, o que contribuirá para melhorar sua prática docente e seu conhecimento, construindo sua identidade profissional.

Conforme Nóvoa (1995, p.25) “A formação não se constrói por acumulação (de cursos, de conhecimentos ou de técnicas), mas sim através de um trabalho de reflexividade crítica sobre as práticas e de (re)construção permanente de uma identidade pessoal". O professor se torna aluno na formação continuada com o intuito de buscar novas alternativas para tornar suas aulas mais atrativas e produtivas, fazendo com que este profissional busque práticas pedagógicas mais dinâmicas, refletindo na aprendizagem de seus alunos.

Mesmo diante da realidade educacional, com inúmeros desafios profissionais, o docente deve buscar atualização constante. É necessário que se crie condições favoráveis para que estes profissionais consigam ter uma formação e valorização, encontrando formas de amenizar as dificuldades. Guimarães (2000) afirma que:

\begin{abstract}
Sabemos que não é fácil, no Brasil, sobreviver dessa profissão (salários baixos, jornada extensa e condições materiais difíceis) nem, tampouco sobreviver nessa profissão, considerando o desgaste físico, emocional e cultural (pouco tempo e estimulo para se atualizar) a que os professores são, em geral, expostos em sua trajetória profissional. Essa realidade torna-se bem mais explicita diante das recorrentes "novas exigências" criadas para cumprimento pelos professores. Nesse contexto, não é fácil o professor desenvolver uma imagem positiva da profissão docente. Mais difícil ainda se aos próprios cursos reforçarem essa imagem negativa do ser professor. (p. 90)
\end{abstract}

Diante dessa realidade acredita-se no potencial da formação para vencer os desafios da prática docente, permitindo que a reflexão sobre o fazer docente, atenue as dificuldades e impulsione uma atitude de desacomodação promovendo mudanças na sala de aula, que poderá refletir na comunidade escolar.

\title{
3. Desenvolvimento das Oficinas
}

As ações desenvolvidas foram permeadas por atividades interativas tais como: rodas de conversa, ambiente virtual de aprendizagem e escritas reflexivas sobre questões previamente elencadas.

\subsection{Oficina "Espaços de Diálogo: $O$ docente Protagonizando sua Prática junto a Universidade"}


A oficina "Espaços de Diálogo: O docente Protagonizando sua Prática junto a Universidade" teve o objetivo de compreender como os docentes veem a formação continuada no viés interdisciplinar, a fim de tornar o professor protagonista das ações propostas nas formações. Essa oficina foi realizada na escola Mascarenhas de Morais na cidade do Rio Grande por integrantes do FORPPE e foi desenvolvida em três encontros presenciais.

No primeiro encontro foi apresentado a oficina e disponibilizado uma leitura reflexiva sobre o assunto. Na sequência foi pedido aos professores que escrevessem uma carta de apresentação contendo um relato sobre a trajetória de suas vidas e o motivo pelo qual escolheram serem professores. Além disso, foi solicitado que escrevessem suas opiniões sobre a formação continuada. Após foi desenvolvida uma atividade interativa em que os docentes depositaram suas cartas, não identificadas, em uma urna. Em seguida, cada docente retirou aleatoriamente uma carta dessa urna e conferiu se a mesma não era de sua autoria. Então se reuniram em uma roda de conversa e fizeram as leituras. Cada docente leu a carta escolhida e teve que relacionar os aspectos escritos no texto com as características de um de seus colegas, lembrando que o conteúdo das cartas é pessoal, mas não confidencial. No decorrer do texto o leitor teve que descobrir o autor da escrita. Quando não era descoberto o autor da carta, eram escolhidos mais dois professores para dar sua opinião, e quando mesmo assim não era descoberto o autor da carta, esse se apresentava ao grupo.

Essa dinâmica objetivou a socialização, em um espaço para interatividade, que traz perguntas e questões para pensar e também mobilizou o diálogo que possibilitou a instauração de problemáticas que indaguem a respeito da situação e das opiniões, conforme suas experiências, mesmo que discordantes.

Foi discutido o tema interdisciplinaridade no segundo encontro, o qual foi embasado na leitura disponibilizada anteriormente. Baseados nas possibilidades que surgiram, os professores foram convidados a se reunirem em grupos menores para a elaboração de um projeto interdisciplinar que foi desenvolvido durante suas práticas pedagógicas. Após esse período de desenvolvimento do projeto, foi realizado o terceiro encontro em que os docentes apresentaram os resultados obtidos com a implantação da proposta em sala de aula. Também ocorreu o compartilhamento das experiências vivenciadas durante as reuniões.

Ao final dessa oficina, houve discussão sobre os limites e possibilidades de desenvolver um projeto interdisciplinar no contexto de sala de aula e o que essas atividades contribuem para a formação, tanto do professor quanto do aluno. Em todo o momento salientou-se o protagonismo docente e o grau significativo de suas ações possuem para o ensino e aprendizagem. Sendo assim, a proposta em desenvolver estratégias interdisciplinares baseadas 
nas experiências dos docentes possibilitou suprir as necessidades dos estudantes em aprender o que faça sentido e que de alguma maneira esteja inserido no contexto da vida. Algo que amplie sua visão de mundo, visão esta não mais fragmentada, mas ampla, no sentido de totalidade. Dessa forma, tanto professor quanto aluno serão participativos no processo de formação.

\subsection{Oficina "O exercício da escrita articulado aos processos de ensinar e aprender de professores e alunos"}

Muitos alunos apresentam dificuldades na compreensão de enunciados e problemas matemáticos e por essa razão os aspectos linguísticos, em especifico a escrita, são interligados aos conceitos matemáticos, o que contribui para a aprendizagem mais significativa. Por isso, foi elaborada a oficina "O exercício da escrita articulado aos processos de ensinar e aprender de professores e alunos". Esta ação foi desenvolvida com alguns graduandos da Universidade Federal do Rio Grande - FURG, especificamente, do curso de Matemática Licenciatura e dois professores da rede pública de ensino participantes do Programa Institucional de Bolsas de Iniciação à Docência e foi desenvolvida em cinco encontro semipresenciais. A estratégia visou incentivar a prática da escrita como mediadora do processo de ensinar e aprender. Este espaço formativo também foi realizado em rodas de conversa e após estudos de referenciais teóricos foi proposta a construção de uma história.

No primeiro encontro foi feito uma roda de leitura no qual os licenciandos puderam ter acesso a histórias de sala de aula disponibilizadas por alguns integrantes do grupo FORPPE. Nesse primeiro contato, cada estudante pode relatar resumidamente a história lida por ele e assim possibilitar o primeiro contato com a leitura nessa atividade. Visando incentivar a prática da escrita como mediadora no processo de ensinar e aprender, as ações dessa oficina favoreceram o estudo de referenciais teóricos que abordaram a escrita como potencializadora nos processos de ensino e aprendizagem da Matemática, como também a aplicação da oficina referente a construção de histórias de sala de aula, a qual gerou rodas de conversas e reescritas dessas histórias.

$\mathrm{Na}$ sequência, no segundo encontro, foi proposto uma roda de conversa com os estudantes com o intuito de mostrar os elementos que compõem uma narrativa. Então ocorreu a produção de narrativa no qual houve uma elaboração da versão inicial da história criada por cada estudante e ela deveria ter um teor educativo envolvendo a Matemática, sendo essa escrita feita a distância e enviada para os integrantes do grupo. Na sequência, foi lida e analisada a escrita de cada história e então se deu a oportunidade da reescrita dessas narrativas. 
Conforme foram finalizadas as reescritas das histórias, foi feito um novo encontro presencial, no qual ocorreu a leitura entre pares. Após lida, os estudantes fizeram sugestões para a sua dupla que novamente pode escrever e finalizar a escrita da história. Por fim, houve a socialização das narrativas, em uma roda de conversa, em que os alunos pegaram uma história aleatoriamente e puderam ler para todos os participantes dessa oficina, sendo assim escolhida entre eles uma a história mais criativa e elaborada. Essa ação promoveu aos professores e alunos inseridos no contexto educativo, oportunidade de ampliar a competência da escrita, bem como, o seu interesse a valorização pela linguagem.

\subsection{Oficina "Construção de Conceitos Matemáticos Utilizando o Software Geogebra"}

A oficina "Construção de Conceitos Matemáticos Utilizando o Software Geogebra". foi oferecida no caráter semipresencial, sendo desenvolvida em oito encontros presenciais e atividades na rede social Facebook. Essa ação foi desenvolvida com alguns professores da Escola Municipal de Ensino Fundamenta Helena Small na cidade do Rio Grande. O intuito dessa ação foi de promover espaços colaborativos de aprendizagem entre os professores da rede municipal de ensino utilizando os dispositivos moveis e o software de geometria dinâmica GeoGebra.

A difusão de dispositivos móveis em todos os setores da sociedade, inclusive na escola, configura novos modos de aprender e de perceber a realidade. A maioria dos alunos utilizam seus smartphones para poder acessar plataformas de pesquisa, redes sociais e registrar momentos das aulas com fotos e vídeos. A utilização dessas ferramentas está mudando, aos poucos o cenário escolar, transformando as relações sociais e criando novas dinâmicas que possibilitam repensar a nossa concepção de sala de aula. A ação explorou algumas estratégias de inserção das tecnologias digitais, neste caso os dispositivos móveis (celulares, tablets, etc) nos processos de ensino e aprendizagem da Matemática. As ações possibilitaram a leitura e discussão de materiais que versam sobre o uso de tecnologias digitais no ensino de Matemática.

Um dos objetivos propostos para esse tipo de oficina foi oferecer vivencias de experimentação do uso das tecnologias digitais em ambientes educacionais e poder utilizar, manusear, visualizar e construir virtualmente objetos geométricas em atividades matemáticas investigativas. Com isso incentiva-se elaborar e explicar atividades matemáticas envolvendo um software como o GeoGebra para estudar alguns conceitos de geometria dinâmica e também, reconhecer o caráter inovador da utilização de smartphones e notebooks como um recurso pedagógico que amplia os espaços educativos. 
A ação começou com uma socialização dos professores que estavam participando dessa oficina. Nesse primeiro encontro, ocorreu um diálogo entre os envolvidos escutando os anseios de alguns professores de matemática da rede pública de ensino e os conteúdos de matemática que eles gostariam de desenvolver nas atividades dessa ação. Após, foi determinado os assuntos eles gostariam de trabalhar no software GeoGebra e então foi escolhido os seguintes temas: Teorema de Pitágoras, Teorema de Tales, número $\pi$. Tangran e Curva de Koch.

No segundo encontro, foi introduzido algumas noções básicas do software GeoGebra para que pudessem desenvolver as atividades propostas com mais facilidade. Para essa atividade foram utilizados netbooks.

As oficinas foram bem recebidas pelos professores das escolas e licenciandos, pois permitiram elaborar um planejamento com base nas necessidades dos professores e estudantes de graduação enfatizando sempre ações que valorizem escuta dos docentes e na formação realizada dentro do espaço escolar Estas oficinas buscaram promover a reflexão acerca dos processos de ensino e a aprendizagem principalmente no que tange a realidade das escolas públicas.

\section{Conclusões}

O Grupo FORPPE teve como objetivo com essas três oficinas discutir e aprofundar estudos relacionados a temática da formação de professores no âmbito da Educação Básica e Superior, sendo assim foi possível verificar nessas três ações que o grupo atingiu esses objetivos. De maneira geral, ocorreu um grande envolvimento de todos os participantes nas ações realizadas. Nesse sentido, as reflexões realizadas possibilitaram a construção de novas oficinas, a serem aplicadas conforme a necessidade e disponibilidade, tantos dos professores das redes de ensino, bem como da comunidade acadêmica. As avaliações das estratégias realizadas pelos participantes e pelo grupo FORPPE, possibilitou buscar e refletir acerca dos processos de ensino e a aprendizagem principalmente no que tange a realidade das escolas públicas tendo o foco de suas ações na escuta aos docentes e na formação realizada dentro do espaço escolar.

O Programa de Formação Acadêmico Profissional e Práticas Educativas propiciou a discussão e o aprofundamento do estudo sobre temas relacionados à formação de professores no âmbito da educação básica e superior. As ações interdisciplinares permitiram transitar nas diferentes áreas e conhecimento de modo a investigar os problemas do ensino e aprendizagem nos diversos contextos, como escola, universidade e comunidade. Desta forma, acredita-se na 
importância de continuar desenvolvendo projetos dessa natureza e ampliando as ações do grupo.

\section{Referências}

DEMO, Pedro. Formação Permanente e Tecnologias Educacionais. Petrópolis, RJ: Vozes, 2006.

FREIRE, Paulo. Pedagogia da autonomia: saberes necessários à prática educativa. São Paulo: Paz e Terra, 1996.

FREIRE, Paulo. Pedagogia da Autonomia. 28. ed. São Paulo: Editora Paz e Terra, 2002. 165p.

GUIMARÃES, Walter Soares. Formação de professores: Saberes, identidade e profissão. $3^{\circ}$ ed. Papiros, 2006.

NÓVOA, Antônio. Os professores e a sua formação. 2 ed. Lisboa: Dom Quixote, 1995. 